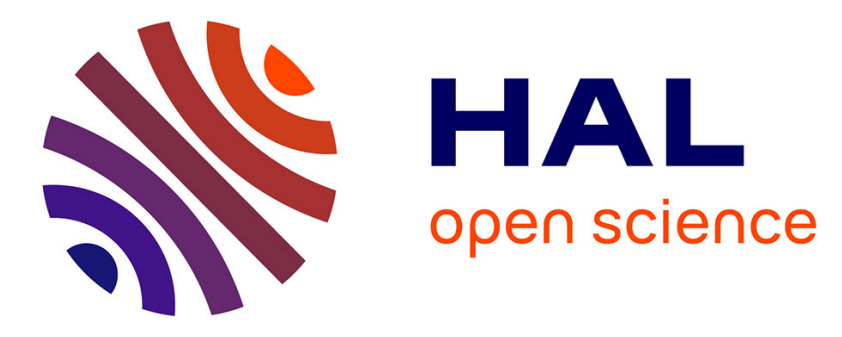

\title{
3D direction-of-arrival estimation using a wideband vector antenna
}

Johan Duplouy, Christophe Morlaas, Hervé Aubert, Patrick Potier, Philippe Pouliguen, Christopher Djoma

\section{- To cite this version:}

Johan Duplouy, Christophe Morlaas, Hervé Aubert, Patrick Potier, Philippe Pouliguen, et al.. 3D direction-of-arrival estimation using a wideband vector antenna. IEEE International Symposium on Antennas and Propagation and USNC-URSI Radio Science Meeting (APS/URSI 2018), Jul 2018, Boston, MA, United States. pp.197-200, 10.1109/lawp.2017.2779878 . hal-01977267

\section{HAL Id: hal-01977267 \\ https://hal-enac.archives-ouvertes.fr/hal-01977267}

Submitted on 10 Jan 2019

HAL is a multi-disciplinary open access archive for the deposit and dissemination of scientific research documents, whether they are published or not. The documents may come from teaching and research institutions in France or abroad, or from public or private research centers.
L'archive ouverte pluridisciplinaire HAL, est destinée au dépôt et à la diffusion de documents scientifiques de niveau recherche, publiés ou non, émanant des établissements d'enseignement et de recherche français ou étrangers, des laboratoires publics ou privés. 


\title{
3D Direction-of-Arrival Estimation using a Wideband Vector Antenna
}

\author{
J. Duplouy* ${ }^{* \dagger}$, C. Morlaas ${ }^{* \ddagger}$, H. Aubert ${ }^{\dagger \ddagger}$, P. Potier ${ }^{\S}$, P. Pouliguen ${ }^{\S}$ and C. Djoma ${ }^{\S}$ \\ *TELECOM-EMA, ENAC, F-31055 Toulouse, France, Email: johan.duplouy@enac.fr \\ ${ }^{\dagger}$ LAAS-CNRS, MINC, F-31400 Toulouse, France \\ $\ddagger$ Toulouse University, F-31400 Toulouse, France

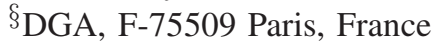

\begin{abstract}
In this communication, direction finding performances of a reconfigurable wideband vector antenna are predicted. The accurate estimation of the direction of arrivals across the 3D half-space of incoming electromagnetic fields is obtained over a 1.7:1 frequency range from only two colocated and orthogonal circular arrays of Vivaldi antennas.
\end{abstract}

\section{INTRODUCTION}

The direction-of-arrival (DoA) estimation of incoming electromagnetic (EM) fields has gained a significant position in numerous civil and defense related applications [1]. Some applications may require a $3 \mathrm{D}$ coverage and wide operating frequency range. Keeping in mind that the estimation accuracy of the DoAs along with the spatial and frequency coverages mainly depends on the electrical performances of the antennas, it becomes important to focus on the development of specific direction finding (DF) antennas with 3D and wideband coverages capabilities. A way to estimate the DoA of an incoming EM field in the 3D space with a compact DF antenna consists of using a Vector Antenna (VA) [2]. Ideal VA is composed of six orthogonal and colocated antennas and combines three electric and three magnetic dipoles. These six dipoles allow the derivation of the DoA from the measurement of the six components of the incoming EM field. Several VA designs covering the $3 \mathrm{D}$ space have been reported. An active VA operating at frequencies below $30 \mathrm{MHz}$ is studied in [3], while some of us proposed in [4] a passive VA for multi-band applications.

The DoA estimation performances of the passive, wideband and reconfigurable VA reported by the authors in [5] are assessed in this communication.

\section{Reconfigurable Wideband Vector Antenna}

The novel passive, wideband and reconfigurable VA, which was recently proposed by the authors [5], is shown in Fig. 1. It consists of two orthogonal and colocated dual-port semicircular arrays of Vivaldi antennas. As specified in Table I, three components of the incoming EM field $\left(H_{x}, H_{y}\right.$ and $\left.E_{z}\right)$ can be measured over a 1.7:1 simulated impedance bandwidth (VSWR $\leqslant 2.3$ ) ranging from $2.08 \mathrm{GHz}$ to $3.56 \mathrm{GHz}$ thanks to the control of the amplitude and phase impressed at the four ports of the VA. The VA is included in a half-sphere of radius $0.52 \lambda_{0}$, where $\lambda_{0}$ is the free space wavelength at the lowest operating frequency.

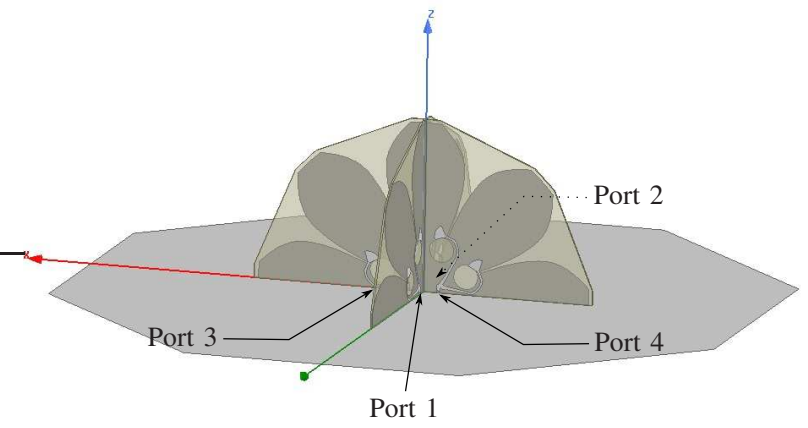

Fig. 1. Topology of the VA reported in [5] and ports numbering description

TABLE I

EXCITATION CONFIGURATIONS FOR THE MEASUREMENT OF THE INCOMING EM-FIELD COMPONENTS

\begin{tabular}{|c|c|c|c|c|}
\hline $\begin{array}{c}\text { Measured } \\
\text { Component }\end{array}$ & Port 1 & Port 2 & Port 3 & Port 4 \\
\hline$H_{x}$ & 1 & $1 \angle 180^{\circ}$ & 0 & 0 \\
\hline$H_{y}$ & 0 & 0 & 1 & $1 \angle 180^{\circ}$ \\
\hline$E_{z}$ & 1 & 1 & 1 & 1 \\
\hline
\end{tabular}

\section{Direction Finding PERFormances}

Two simulated configurations are considered here to evaluate the DoA estimation performances of the reconfigurable wideband VA: (1) the antenna is mounted on an infinite ground plane, and (2) the antenna is mounted on a finite metallic and octagonal support with a circumcircle radius of $1.13 \lambda_{0}$. DoAs are estimated in the 3D half-space using the well-known MUSIC algorithm (MUltiple SIgnal Classification) [6] and from full-wave EM simulations (HFSS software). Each DoA is defined by the azimuth angle $\phi \in\left[0 ; 360^{\circ}\right]$ and elevation angle $\theta \in\left[0 ; 90^{\circ}\right]$. The accuracy of the DoA estimation is derived from the computation of the Root-Mean-Square error of the angular distance, denoted by $\Delta a_{\mathrm{RMS}}$, between the estimated DoA and the actual DoA (see, e.g., [4] for the detailed definition of $\Delta a_{\text {RMS }}$ ). Furthermore, the evaluation of the estimation performances is based on the following assumption: only one vertically polarized EM-wave is incident upon the VA. Other estimation parameters used for performing the simulations are summarized in Table II. Following [4], a calibration matrix derived from simulated radiation patterns 
of two magnetic and one electric dipoles is used to take into account eventual amplitude and phase distortions in the radiation patterns.

TABLE II

PARAMETERS USED FOR THE EVALUATION OF THE DIRECTION FINDING PERFORMANCES

\begin{tabular}{|c|c|}
\hline DoA Algorithm & MUSIC \\
\hline Number of incoming EM fields & 1 \\
\hline Polarization of the incoming EM fields & Vertical \\
\hline Angular coverage & $\phi \in\left[0^{\circ} ; 90^{\circ}\right]$ \\
$\theta \in\left[0^{\circ} ; 90^{\circ}\right]$ \\
\hline Angular resolution & $\Delta \phi=5^{\circ}$ \\
$\Delta \theta=2^{\circ}$ \\
\hline Incoming EM fields power density & $-105 \mathrm{dBW} \cdot \mathrm{m}^{-2}$ \\
\hline Noise power level & $-111 \mathrm{dBm}$ \\
\hline Incoming signal power density to noise ratio & $36 \mathrm{~dB} \cdot \mathrm{m}^{-2}$ \\
\hline Snapshots per DoA estimation & 100 \\
\hline Number of estimations per DoA & 20 \\
\hline & $2.2 \mathrm{GHz}$ \\
Frequencies used the DoA finding & $2.8 \mathrm{GHz}$ \\
& $3.4 \mathrm{GHz}$ \\
\hline
\end{tabular}

Fig. 2 reports the simulated Root-Mean-Square of angular distance $\Delta a_{\mathrm{RMS}}$ at three operating frequencies in the bandwidth of the VA. For both configurations, it can be observed that the $\Delta a_{\mathrm{RMS}}$ does not exceed 5 degrees in almost every directions in the 3D upper half-space within the antenna bandwidth. Furthermore, highest values of $\Delta a_{\mathrm{RMS}}$ are found in specific directions depending on the operating frequency and the configuration (infinite or finite ground plane). However, it can be observed that the use of the finite ground plane does not significantly degrade the estimation performances. From the simulation results reported in Table III, where the 95th and 99th percentiles of the $\Delta a_{\mathrm{RMS}}$ (which indicate the errors threshold for respectively $95 \%$ and $99 \%$ of all the obtained DoAs) are given, it can be predicted that the VA is suitable for $3 \mathrm{D}$ direction finding estimation with a very good estimation accuracy.

TABLE III

DF PERFORMANCES PREDICTED FROM FULL-WAVE ELECTROMAGNETIC SIMULATIONS

\begin{tabular}{|c|c|c|c|}
\hline \multicolumn{5}{|c|}{ Infinite ground plane } \\
\hline Frequency & $\max \Delta a_{\mathrm{RMS}}$ & 99 th $\Delta a_{\mathrm{RMS}}$ & 95 th $\Delta a_{\mathrm{RMS}}$ \\
\hline $2.2 \mathrm{GHz}$ & $2.8^{\circ}$ & $2.3^{\circ}$ & $1.5^{\circ}$ \\
\hline $2.8 \mathrm{GHz}$ & $4.0^{\circ}$ & $3.1^{\circ}$ & $2.3^{\circ}$ \\
\hline $3.4 \mathrm{GHz}$ & $85.2^{\circ}$ & $12.0^{\circ}$ & $2.1^{\circ}$ \\
\hline \multicolumn{4}{|c|}{ Finite ground plane } \\
\hline Frequency & $\max \Delta a_{\mathrm{RMS}}$ & 99 th $\Delta a_{\mathrm{RMS}}$ & 95 th $\Delta a_{\mathrm{RMS}}$ \\
\hline $2.2 \mathrm{GHz}$ & $4.2^{\circ}$ & $2.4^{\circ}$ & $1.7^{\circ}$ \\
\hline $2.8 \mathrm{GHz}$ & $3.8^{\circ}$ & $2.8^{\circ}$ & $2.0^{\circ}$ \\
\hline $3.4 \mathrm{GHz}$ & $142.5^{\circ}$ & $51.8^{\circ}$ & $1.6^{\circ}$ \\
\hline
\end{tabular}

\section{CONCLUSION}

The DF performances of a reconfigurable wideband VA which emulates two magnetic and one electric dipoles is presented, showing a design with a high level of DoA estimation accuracy over a 1.7:1 frequency range with a 3D field of view. Experimental validations of these predicted performances are on tracks.

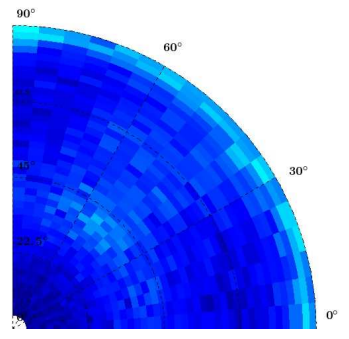

(a)

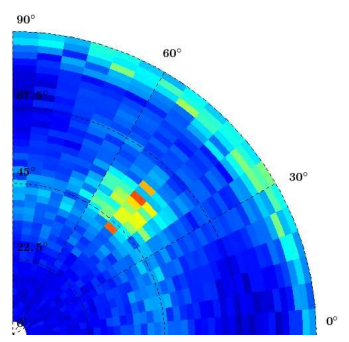

(c)

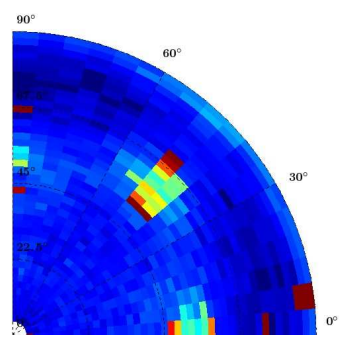

(e)
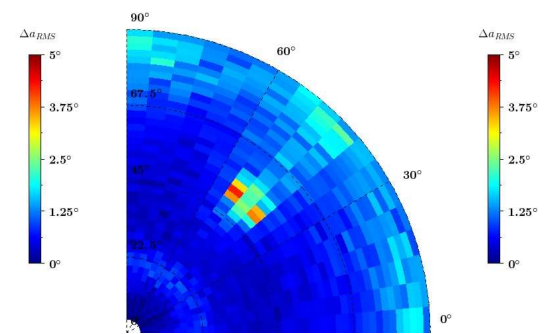

(b)
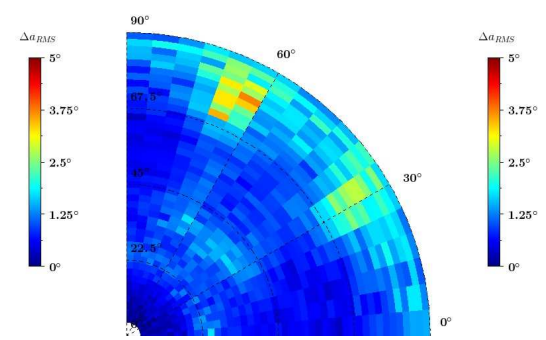

(d)
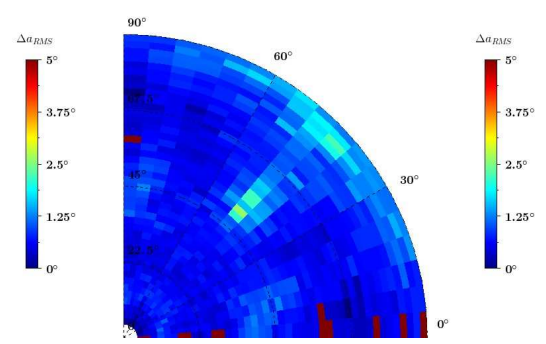

(f)
Fig. 2. Simulated $\Delta a_{\mathrm{RMS}}(\phi, \theta)$ at: (a) \& (b) $2.2 \mathrm{GHz}$, (c) \& (d) $2.8 \mathrm{GHz}$, and (e) \& (f) $3.4 \mathrm{GHz}$ when the reconfigurable wideband VA is mounted on an infinite ground plane (left figures) or on a finite octagonal ground plane (right figures). Elevation angles $\theta$ are given on the radial axis and azimuth angles $\phi$ are given on the angular axis.

\section{ACKNOWLEDGEMENT}

The authors would like to thank the French Defense Agency (Direction Général de l'Armement, DGA) and the Occitanie regional council for their financial support.

\section{REFERENCES}

[1] T. E. Tuncer and B. Friedlander, Classical and Modern Direction-ofArrival Estimation. Academic Press, 2009.

[2] A. Nehorai and E. Paldi, "Vector-sensor array processing for electromagnetic source localization," IEEE Transactions on Signal Processing, vol. 42, no. 2, pp. 376-398, Feb. 1994.

[3] B. Almog, "Compact 3D direction finder," Patent, Mar. 20, 2013, EP20120184835.

[4] J. Lominé, C. Morlaas, C. Imbert, and H. Aubert, "Dual-band vector sensor for direction of arrival estimation of incoming electromagnetic waves," IEEE Transactions on Antennas and Propagation, vol. 63, no. 8, pp. 3662-3671, Aug. 2015.

[5] J. Duplouy, C. Morlaas, H. Aubert, P. Pouliguen, P. Potier, and C. Djoma, "Reconfigurable grounded vector antenna for 3D electromagnetic direction finding applications," IEEE Antennas and Wireless Propagation Letters, accepted in 2017, in press, doi: 10.1109/LAWP.2017.2779878.

[6] R. Schmidt, "Multiple emitter location and signal parameter estimation," IEEE Transactions on Antennas and Propagation, vol. 34, no. 3, pp. 276-280, Mar. 1986. 